IRA-International Journal of Management \& Social Sciences

ISSN 2455-2267; Vol.07, Issue 02 (2017)

Pg. no. 178-186

Institute of Research Advances

http://research-advances.org/index.php/RAJMSS

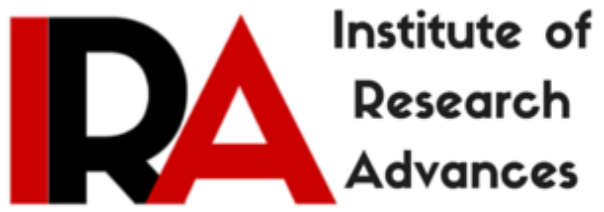

\title{
Exploring the Universality of Feminine Subjugation
}

Tabzeer Yaseen

Ph.D. Scholar, Department of Political Science, University of Kashmir - 190006, India.

Type of Review: Peer Reviewed.

DOI: http://dx.doi.org/10.21013/jmss.v7.n2.p7

How to cite this paper:

Yaseen, T. (2017). Exploring the Universality of Feminine Subjugation. IRA-International

Journal of Management \& Social Sciences (ISSN 2455-2267), 7(2), 178-186.

doi:http://dx.doi.org/10.21013/jmss.v7.n2.p7

(C) Institute of Research Advances

(cc) EY-NC

This work is licensed under a Creative Commons Attribution-Non Commercial 4.0 International License subject to proper citation to the publication source of the work.

Disclaimer: The scholarly papers as reviewed and published by the Institute of Research Advances (IRA) are the views and opinions of their respective authors and are not the views or opinions of the IRA. The IRA disclaims of any harm or loss caused due to the published content to any party. 


\begin{abstract}
History is witness to the fact that women have been the objects of suppression and subjugation in the world. This oppression has been institutionalized in nearly all the societies of the world. The end result of this process of institutionalization has been the absence of women from the corridors of power, her absence from the fields of knowledge production, her absence in the histories of their places. The objective of this paper is to analyze the near universality of this feminine absence in history. What are the factors that led to this situation and how did feminity end up being valued as 'inferior' in comparison to 'masculine' attributes. This led to her existence being limited and defined by her corporal self. The end result is that one half of the population of the world had to live a miserable life till feminism emerged on the scene. This paper also traces the emergence of feminism as a reaction to this universality of feminine subjugation. The methodology adopted has been textual and literary analysis.
\end{abstract}

Keywords: women, feminism, domination, exploitation, subjugation, gender

\title{
1. Introduction
}

"Everywhere we find that women are excluded from certain crucial economic or political activities, that their roles as wives and mothers are associated with lesser powers and prerogatives than are the roles of men. It seems fair to say then, that all contemporary societies are to some extent male-dominated, and although the degree and expression of female subordination vary greatly, sexual asymmetry is presently a universal fact of human social life." (Rosaldo and Lamphere, 1974: 3)

There are no second arguments about the fact that the experience of women in society hasn't been the same as that of men. However, what is the reason that this difference is expressed in subjective terms giving rise to the subjugation of women and the corresponding superiority of men? The traditionalists would of course rest the case in biological determinism arguing that there is something hereditarily intrinsic to males that makes them the dominant sex. This "something" on the other hand, is missing in females which make them feel secure in this position of natural subordination which also caters to their maternal instincts. There are some who claim that the inequality between the two has existed since times immemorial, whereas as there are other thinkers who believe that the inequality and oppression women experience is a part of a long historical process which occurred hand in hand with the institutionalization and systematization of other types of inequalities, especially those of the class. Whatever the explanation, a look at the social structure justifies the presence of a patrilineal descent principle - the unconditional authority of father in the family and the importance of sons. In this context, it is observed that:

Absolute equality of opportunity is clearly incompatible with any positive solidarity of the family. ...Where married women are employed outside the home, it is, for the great majority, in occupations which are not in direct competition for status with those of men of their own class. Women's interests, and the standard of judgment applied to them, run, in our society, far more in the direction of personal adornment.... It is suggested that this difference is functionally related to maintaining family solidarity in our class structure. (Parsons, 1942: 174)

A classic account of the underlying reason behind the universality of feminine subordination has been given by Sherry B. Ortner (b.1941), an American cultural anthropologist, in her influential paper, "Is Female to Male as Nature Is to Culture?" wherein she compares females to nature and explains in detail the reason for the secondary status of women in any given society - a pan cultural fact. She says, "The universality of female subordination, the fact that it exists within every type of social and economic arrangement and in societies of every degree of complexity, indicates to me that we are up against 
something very profound, very stubborn, something we cannot rout out simply by rearranging a few tasks and roles in the social system, or even by reordering the whole economic structure...the underlying logic of cultural thinking that assumes the inferiority of women." (Ortner, 2001: 61) Thus she stresses on cultural evaluations to come to the conclusion that women, in every known culture, are to some degree inferior to men. Ortner attempts to look into the case of female subordination in the light of "other universals" which she defines as "factors built into the structure of the most generalized situation in which all human beings, in whatever culture, find themselves". It is here that the category of nature: female and male: culture comes in and therefore the whole debate begins with the body of females having procreative functions. Since it is always culture's project to subsume and transcend nature, if women were considered part of nature, then culture would find it "natural" to subordinate, not to say oppress, them. (Ibid.) The outcome of this whole process is that woman comes to occupy an intermediate position between the two extremes of culture and nature. She has remained and will remain within the tight boundary of these binaries till the cultural valuations are changed or considerably altered.

The prevalence of female subjugation can be witnessed in nearly every culture of the world. Various reasons can be attributed to the universal presence of the fact that women continue to be dominated by men. Firstly, it is a woman's physiology, social role and psyche that is seen as closer to nature which in turn gives man the opportunity to take control of women's bodies, sexuality and even their existence. Secondly, Schneider drew attention to the fact that, since inheritance and succession in matrilineal societies supposedly passed from mother' brother to sister's son, women played secondary decision making roles, even in matrilineal societies. (Poewe, 1980: 112) Schneider argues that though women look after children but it is men who have the final authority in matters relating to their wives and children.

In Western culture the representation of women as frivolous, evil, dissipate rested in part on the myth of Eve bringing sin into the world, but images of female decadence and ignorance could be found in Chinese and Indian civilizations as well. (Freedman, 2007: xiv) Had women not been the universally subjugated sex then the presence of a plethora of feminist writings across regional and geographical boundaries wouldn't have been possible. In response to the prevalent negative stereotypes, one can find writers from the early fifteenth century like Christine de Pizan in the West to Qasim Amin in the East who wrote against the prevalent customs and traditions that put women at a disadvantageous position in society. The point in question is not whether these writers took the same approach while putting forward their claim of women emancipation but the fact is that the question of female subordination is common to both, though their writings are separated by a span of four centuries.

\section{Reading Power in Gender Discourse}

"Biology isn't destiny", is the slogan of activists who call on for gender justice by drawing a sharp contrast between sex and gender. Biology shouldn't be a denominator of the social and political roles that an individual is supposed to play in the world, the society or the family of which he or she is a part.

When distinctions are made between males and females in terms of their social status and role, it is called "Gender". Though commonly the terms sex and gender are used interchangeably but there is a difference between the two when we see to it through the lens of political and social phenomena. Whereas sex denotes only the physical aspect of a body; gender looks into the cultural or social definitions that are attached to a particular sex. Therefore when subjective valuations are attached to the meaning of sex, we enter into the debate of "gender discourse". Gender is thus a social construct and usually operates through stereotypes of 'feminity' and 'masculinity'. (Heywood, 2011: 204) But the more mundane reproduction of gendered identity takes place through the various ways in which bodies are acted in relationship to the deeply entrenched or sedimented expectations of gendered existence. (Butler, 1988: 524) There is a complex inter-relationship that occurs at the back, when we try to define gender. One can identify this inter-relationship at three levels, i.e. between - 'the gender biology' i.e. sex of the individual; 'the gender identity' i.e. how an individual perceives one's inner sense of self in the form of being a male, a female, neither of them or both of them; and finally 'the gender expression' i.e. the expression or outward presentation of one's self. It is this interaction of these three dimensions of gender that distinguishes gender as a peculiar and complex phenomenon which gives shape to the manner in which one produces 
how gender can be explained in their own authentic sense. This involves a two way process of how one experience's one's gender situation and secondly, how is it that other people perceive them?

There is no denying the fact that 'gender is everywhere'. The decade of 1970s saw a preoccupation with justifying the existence of gender in the daily lives of people. That is to say that upon showing that the differences and divisions between men and women can't be accounted for by biological difference, and that the culturally dominant ideas about masculinity and femininity are stereotypes which correspond only crudely to reality.(Marshall, 2004: 250) Gender is actually handed over to a human being as soon as he or she is born. We are constantly bombarded by gender messages and expectations. At the familial level baby boys and girls are transformed into adult males and females through the process of socialization. On the other hand, at the structural level the same process is carried out simultaneously through unequal division of labour in the society (even between those males and females who are having full time jobs); discrimination in employment where sex rather than skills determine who goes up the ladder and who remains at the bottom; discrimination in the public sphere where she is seen as the 'Other' who still fails to get representation at the highest levels of legislature ${ }^{1}$, executive or the judiciary. Culture, Socialization, peers, schools, community, state, media and even religion are some of the many influences that happen to shape one's understanding of this central aspect of self. There is no debating or questioning about the fact that it is only a woman who can give birth to a child but this child rearing capacity should in no way determine her social position in society nor should it put her at a disadvantageous position but the reality is the other way round. The link between childbearing and child-rearing is cultural rather than biological: women are expected to stay at home, bring up their children and look after the house because of the structure of traditional family life. (Heywood, 2007: 237) Sex differences can't be used a justifying factor for gender distinction and the latter highlights the point that biological differences between men and women can't in any way be a means of legitimizing their positions and social roles. It has therefore been argued that gender is a political category imposed by patriarchy and reproduced through a process of conditioning that operates mainly through the family. (Heywood, 2011: 204) This implies reading gender through the prism of power leads to the concept of Patriarchy.

Gender is a politically significant social cleavage just like racism, social class, creed or even for some, religion. Though, both the sexes are dependent on each other as they seem to be parts of a whole which when together come out as the best of unions. But how is it that over time the relations between these two sexes became enmeshed in a multidimensional power structure? A theory of 'sexual politics' is the best means to answer the above question through the concept of 'patriarchy'. The word 'patriarchy' has been derived from the Latin word 'pater' meaning 'father'. Therefore, patriarchy literally means, 'the rule of the father'. Sylvia Walby (b. 1953) in Theorising Patriarchy (1990) defines it as, "a system of social structures and practices in which men, dominate, oppress and exploit women."There are some who limit the meaning of this term only to the private sphere of the family thereby meaning a structure where the dominance and rule of the husband or father symbolizes exploitation. Concurrently, the terms like 'male dominance' or 'male exploitation' are reserved for those relations that take place outside the structure of the family, in society at large. However, there are others who argue that the dominance of the man within the family is a reflection of his dominance at every institutionalized level of the society. Many would argue that the systematic process of male domination stems from the roots of a patriarchal family ties. This is turn reproduces male dominance in all other walks of life: in education, work and last but not the least in politics. In a nutshell, patriarchy when used in its broadest of senses implies 'rule by men'- within as well as outside the family. Hence patriarchy draws attention to the totality of oppression and exploitation to which women are subject which is reflected in the slogan, "The personal is the political". Kate Millet's 'Sexual Politics'(1970) sets the stage for the first systematic account of the theory of patriarchy. Millet argues in this trendsetting book that in all societies till date, the basis of relationship between males and females is 'power', which is therefore political. This power has taken the form of male

\footnotetext{
${ }^{1}$ United States of America, the country which is considered to be the upholder of the true democratic system has never had a female President till date.
} 
domination in all walks of life over women. What is interesting to note is that this power equation appears totally natural or normal because it has internalized itself by appearing as a universal principle for the society to function smoothly. Therefore the existing political institutions inadequately look into the grievances of this subordinated group and they are not encouraged to be an active part of the prevalent political struggles. Quite in the same manner, a disinterested examination of our system of sexual relationship must point out that the situation between sexes now, and throughout history, is a case of that phenomenon Max Weber defined as herrschaft, a relationship of dominance and subordinance. (Millet, 2000: 24-5) According to Kate Millet, this system gives rise to an indigenous form of "interior colonization" whereby males rule females through institutional means. This is so because our society, like all other historical civilizations, is a patriarchy. (Ibid.: 25) This fact is evident if we look at every avenue of power in the society, be it industry, military, universities, science, political office including police. Millet assumes that if patriarchal government is to be the highest form of authority in a society which controls the other half of the population, i.e. females; then two principles of patriarchy can be discussed. Firstly, 'male shall dominate female' and secondly, 'elder male shall dominate younger', suggesting that a patriarchal society is typified by intertwining systems of sexual and generational oppression. On the other hand, Gerda Lerner (1920-2013), the author of "The Creation of Patriarchy" (1986) is strongly against these causal theories of origin of patriarchy that locate the emergence of patriarchy in one historical moment. She studied archaeology, history, art as well as literacy to prove that patriarchy actually is a cultural construct. Lerner gives an interesting account of how gender inequalities were incorporated into the ancient states through slavery, patriarchal family, private property as well as the establishment of a class society. Overly simple origin questions are subsumed by questions about historical process (never "an event") in which changes in kinship organization and economic relations, the establishment of religious and state bureaucracies, and the ascendency of male gods are revealed to contribute materially and symbolically to the evolution of gender-based systems. (Barnes, 1988: 858) She goes on to explain in her another book, The Creation of Feminist Consciousness that "Men develop ideas and systems of explanation by absorbing past knowledge and critiquing and superseding it. Women, ignorant of their own history [do] not know what women before them had thought and taught. So generation after generation, they [struggle] for insights others had already had before them, [resulting in] the constant inventing of the wheel." (Lerner, 1993: 227) Gerda Lerner believes that patriarchy can be ended through a historical process because it was historical process in itself that established society, therefore the institutions that came to be established with time can be removed through the same historical process.

Despite a range of writings on patriarchy, there are disagreements when it comes to understanding the term as many prefer to use the term "gender oppression" instead of patriarchy. Michele Barrett argues that the use of this term more often leads to confusion when the literal meaning of the term is compared with its wider meaning. Moreover, the manner in which patriarchy is defined makes it a static concept which ignores the dynamism of the changing relations between males and females. Therefore, "we should not underestimate the significance of that aspect of gender control as a force restraining women from full participation in the process of creating thought systems". (Barret and McIntosh, 1980: 15) In societies where multiple patriarchies in the form of different castes, creeds, classes, tribes and religion are present, it is nearly impossible to come up with singular narratives of patriarchy. In such a system accepting men as the principal oppressor isn't easily. Similarly Sheila Rowbotham (b. 1943) argues that patriarchy denotes a situation that corresponds to universalistic and historic tendencies which deceives a reader that single causal theories for the emergence of the phenomenon can be located, whereas reality is the other way round. It would be interesting to note that it is because of the presence of these multiple unequal patriarchies which are a byproduct of cleavages along caste, class and communal lines that a unified theory for the explanation of the different facets of this patriarchy needs to be made. There is a need to conceptualize the complex articulation of different patriarchies, along with the distinct and equally challenging question of how subaltern genders are relating to questions of power in the current conjecture. (John, 2004: 66) The binaries through which gender is viewed only in terms of the male and the female sex isn't enough to capture the variation of sex that is prevalent in the society. Hence this spectrum of 
anatomical variation has to be transcended at one point of time so that limiting the study of patriarchy to binaries can be done away with, spreading its scope across a continuum of possibilities. Moreover there are multiple domains that define gender. Thereafter, independent variables can be interconnected to form a theory of patriarchy that is relevant to the contemporary times.

The essence of patriarchy lies in the fact that it draws attention to the political relationship that is present between males and females and secondly, it highlights the significance of gender. Whereas conventional political theorists treat gender relations as innate, the advocates of women's rights view them as part and parcel of the political institutions representing male power. Whether we talk of contemporary or historical societies, patriarchy is evident in every society - it is systemized, all-encompassing and institutionalized. Patriarchy derives its support from the hierarchal and unequal power relations between men and women thereby imposing femininity and masculinity stereotypes in society. The nature and definition of patriarchy has changed over time in consonance with the change in gender relations from time to time. The extent of control and power over women's bodies, their sexuality or even identity varies not only from time to time but also from one place to the other. For instance, the form of subordination of women in East is different from those in the West, again marked differences can be seen in the pattern of exploitation of women in the developing and developed countries. Therefore, it can be said that the term has a much broader meaning and scope in time and space. It can be argued that this form of control finds its development in the historical process and is legitimized and institutionalized by various ideologies, social observances and institutions such as the family, caste, religion, media, law as well as the society. One can say that it was the emergence of the feminist movement which provided the platform for the amalgamation of all those voices calling for the establishment of a gender just society.

\section{Introducing Feminism and the Feminist Theory}

Feminism is a recent term that was coined for the time in the nineteenth century although the intellectual history of the same dates back to over half a millennium when we can see feminist views being expressed in many different cultures. For centuries European writers have tried to come up with a plausible explanation for the "querelles des femmes" (woman question). This feminist consciousness can be traced back to as far as the ancient civilisations of Greece and China. For instance, Plato gives women the right to be a part of the guardian class in his book, The Republic (Vol. V). Hence it wouldn't be wrong to say that Plato adopted a gender free view of political capacities, though his theory is elite in it character restricting the entry of a limited number of women in the guardian class. Similarly, Book of the City of Ladies published way back in France 1405 by Christin e Pisan (1365-c. 1430) is another classic account of the ideas of a woman who wanted to advocate women's right to political influence and education. She also chronicles an account of the famous women of the past in her book. Over the next six hundred years, feminists continued to place female education at the foundation of their quest to achieve women's full humanity. (Freedman, 2007: 3) Another French writer who broke down with the tradition of depicting women as the physically and mentally inferior sex is Fransois Poullain De La Barre (1647-1723) who writes in On the Equality of the Two Sexes published in 1673 by arguing that a person's sex can never be the determining factor for the level of learning of knowledge that he/she can achieve. It was quite uncommon for men at that time to speak for the other half of the population but Barre just did that, he didn't succumb to the conventions of the time. Though he was quite unpopular in his own times but it was Beauvoir who took him out of the annals of history and presented him as one of the earliest champions of women's empowerment. He says, "Since there seems not to be any greater difference between the minds of the two sexes, we can say that the difference does not lie there. It is rather the constitution of the body, but particularly education, religious observance, and the effects of our environment which are the natural and perceptible causes of all the many differences between people." (Ibid.: 11) At that point o f time, the prevalent notion about women's moral, physical, and intellectual inferiority were in vogue that justified patriarchal laws requiring female subservience to husbands and husbands. Therefore, it wouldn't be wrong to say that the woman question has been provoking debates since the fifteenth century itself but these books remained as isolated texts which couldn't garner the large support of the society to gain the 
shape of a movement calling for ending this "institutionalized isolation" of woman folk as passive human beings. This central idea has over the times became the linchpin for a variety of feminist ideas that still today inspire political movements all over the world.

However, it wasn't up till the nineteenth century that an organized women's movement advocating for the rights of women developed. This movement came to be known as "Feminism". The credit for introducing or writing the first text of modern feminism is usually attributed to the British writer, Mary Wollstonecraft (1759-97) who wrote the seminal text, Vindication of the Rights of Woman in 1792. Enlightenment political theory had put to fore the individual rights of man in place of the divine right of king, but to the utter disappointment of those who wanted the laws to be applicable to every citizen irrespective of their sex, the same principles were out of bounds for women. The unique feature of this book was that it was written in the backdrop of French Revolution and Wollstonecraft made use of this opportunity to espouse the cause of female education and empowerment based on same principles which led to the revolution in the first place. The artificial weakness in women's character, according to Wollstonecraft was created due to the socialization of middle class and elite women whose identity revolved only around idle pleasures and beauty. She says:

...I wish to persuade women to endeavour to acquire strength, both of mind and body, and to convince them, that the soft phrases, susceptibility of heart, delicacy of sentiment, and refinement of taste, are almost synonymous with epithets of weakness, and that those beings who are only the objects of pity and that kind of love, which has been termed its sister, will soon become objects of contempt. (Wollstonecraft, 2012: 20)

If in terms of its political lineage is to be seen, then it can be said that 'feminism' is a twentieth century invention and became a familiar part of the academic language since 1960s. The term was coined in France around the later half of 1880 s by HubertineAuclert. She introduced the term for the first time in her journal La Citoyenefor criticizing male dominance and claimed women's rights for emancipation as promised by the French Revolution. Historian of feminisms Karen Offen has demonstrated that since its initial appearance the term has been given many meanings and definitions; it has been put to diverse uses and inspired many movements.(Badran, 2009: 243) Andrew Heywood defines Feminism in his book, Key Concepts in Politics, as, "A political role and ideology that aims to advance the social role of women". There are two basic values around which the claim of feminism revolves - firstly the disadvantage that women suffer is because of their sex, and secondly, this disadvantage needs to be and has to be done away with. Therefore, feminists have made it a point to highlight the political relation that exists between the sexes where one sex becomes the oppressor/ subject and the other becomes the oppressed/object. This viewing of gender dissections as 'political' has been the characteristic feature of feminism in challenging the 'mobilization of bias. (Heywood, 2007: 230) This mobilization was present in the political thought through which the male thinkers were unwilling to explore or look deep into the advantages that they had enjoyed on account of their sex which in turn kept women off the political agenda of thought for a long time. Majority of the feminists, therefore, embrace the goal of sexual equality but it would be wrong to explain feminism in such a narrower sense. Most feminists argue that there is a difference between equality and liberation; the former implying that women should be given opportunities to be like men. The aim of the feminist movement isn't to rob women of their essence and to make them like men, rather it is to allow women the opportunity to develop their own individualities and identities by removing the obstacles that society, customs, institutions, state, politics or even religious structures have created for them irrespective of the part of the world they belong to. The focal point in feminism is patriarchy that draws attention to the whole gamut of exploitations that women face both in the private as well as the public sphere that is independent of time and space. This in turn highlights the importance of the role of gender in the lives of people and how it is that the stereotypes of masculinity and femininity operate within this narrow boundary of gender discourse. Hence feminism has gained increased respectability as an idiosyncratic school of political thought. It has shed new light upon established concepts such as 
power, domination and equality, but also introduced a new sensitivity and language into politics related to ideas such as connection, voice and difference.(Heywood, 2011: 60)

Based on the understanding and the principles of feminism, one can locate the emergence of the feminist theory. In trying to differentiate sex from gender, feminist theory has rejected causal explanations that give primacy to the social meaning of sex. Feminist theory, therefore believes that there has been a systematic manner throughout history by which women have been treated differently than men. It can be said that feminist theory is a philosophical and theoretical arm of feminism which applies feminist principles to many fields like epistemologies, bodies, language and last but not the least psychoanalysis. By focusing on 'epistemologies', the creation and generation of knowledge has been a fundamental part of feminist theory. Women's experiences therefore become the standpoint from seeking to replace conventional gender perspectives. Feminist theory has also focused on how women tend to be associated with 'bodies' while men are associated with the mind which results in justifying the objectification or commodification of women. The body is seen as a mode of enact possibilities which offer the reader a way to understand the ways and means by which cultural conventions are enacted and embodied. Changing 'language' by making it more gender sensitive is another field of focus for feminist theorists as they argue that the masculinization of language has done much harm in perpetuating male domination. Similarly, the theory of psychoanalysis which draws much of its conclusion from Freud is criticized in the feminist theory. The basic assertion is that an individual's psychological sexual development plays a big role in developing the so called masculine and feminine traits which are a result of experiences in early childhood.

Therefore, feminist theory has focused on understanding the way in which pervasive or systematic cultural and political structures work together to perpetuate the myth of female as the "Other". The personal becomes an all-encompassing category of analysis. There are four concerns that feminist theorists generally share. They are: 1) Gender relations are dynamic and therefore historical products that can be reconstituted. More particularly, feminist theorists are concerned with challenging the myths surrounding women's realities, thereby constructing theories for and by women. 2) All institutional and social relations are seen through the prism of gendered relations. This answers the ambiguities relating to what women are and who is doing what for whom. 3) Social change is expressed clearly in political terms challenging all the arrangements which favour males over females, white over non-white, developed over under developed and universal over particulars. 4) The prevalence of other forms of inequalities in social and political life are related and compared with gender inequalities, as the latter is considered a part of this whole matrix of problems. Since the debate revolving around the question of woman spans over a large period of human history, tracing its evolution will help in uncovering the different nuances of the phenomenon and its emergence as a moment.

\section{Conclusion}

The corporeal aspect of a woman's identity has played a big role in establishing her status in society. This is nearly a universal aspect of human existence with women being relegated to the background of the hierarchal structure of the society. Her biology determined her place in politics, religion, law, society which ultimately became entrenched into the institutional fabric of society. Moreover, her reproductive capacity has been used and is still being used as a pretext to explain why a woman is the "Other" while a man is the "Norm". This otherizing process starts right from the time of her birth, becomes more and more visible and effective when she enters adulthood. The feminist scholarship that emerged in the form of feminist theory addressed this concern. It has done so by criticizing the classical western thought and looking back into history to evolve examples of feminist scholarship who denounce the practice of viewing woman through the perspective of her 'body'. This has been a universal truth be it Western or Eastern societies. 


\section{References}

1) Badran. M. (2009). Feminism in Islam: Secular and Religious Convergences. Oxford: Oneworld Publications.

2) Barnes, N. (1988) Review of The Creation of Patriarchy. The University of Chicago Press, 13.4, 857859.

3) Barret. M. and McIntosh. M. (Summer, 1980). The 'Family Wage': Some Problems for Socialists and Feminists. Capital and Class, 4.2.

4) Beauvoir, S. D. (1949). Le DeuxièmeSexe. Paris: Gallimard.

5) Beauvoir, S. D. (2011). The Second Sex (C. Constance Borde\& S. Malovany-Chevallier, Trans.). New York, USA: Vintage Books.

6) Butler, J. (1988). Performative Acts and Gender Constitution: An Essay in Phenomenology and Feminist Theory. Theatre Journal, 40.4, 519-31

7) Einstein. Z. (1981). The Radical Future of Liberal Feminism. London: Longman.

8) Freedman, E. B. (2007). The Essential Feminist Reader. New York: The Modern Library.

9) Greer, G. (1970). The Female Enunch. New York: McGraw-Hill.

10) Heywood, A. (2007). Political Ideologies: An Introduction (4 ${ }^{\text {th }}$ ed.). New York: Palgrave Macmillan.

11) Heywood, A. (2011) Key Concepts in Politics. New York, USA: Palgrave Macmillan.

12) Hoffman, J. and Graham, P. Introduction to Political Theory. New Delhi: Pearson Education.

13) John. M. E. (2004). Feminism in India and the West: Recasting a Relationship. In Maitrayee Chaudhuri (Ed.), Feminism in India. Delhi, India: Kali.

14) Lennon, K. (Fall 2014). Feminist Perspectives on the Body. ed. Edward N.Zalta, The Stanford Encyclopedia of Philosophy. Web. 10 Oct. 2015

15) Lerner. G. (1993). The Creation of Feminist Consciousness: From the Middle Ages to EighteenSeventy. New York: Oxford University Press.

16) Mill. J. S. (1869) The Subjection of Women.

17) Ortner, S. B. (2001). Is Female to Male as Nature is to Culture? In Darlene M. Juschka (Ed.), Feminism in the Study of Religion. Great Britain: Continuum.

18) Marshall, G. (Ed.) (2004) Gender. In Oxford Dictionary of Sociology ( $1^{\text {st }}$ Indian ed.)

19) Millet, K. (2000). Sexual Politics. Urbana: University of Illinois Press.

20) Parsons, T. (1942). An Analytical Approach to the Theory of Social Stratification. In Henry A. Bowman (Ed.), Marriage for Moderns. New York, USA: McGraw Hill.

21) Poewe, K. O. (1980). Universal Male Dominance: an Ethnological Illusion. Springer, 5.2, 111-125.

22) Rosaldo, M. Z and Lamphere, L. (1974). Woman, Culture and Society. Stanford, California: Stanford University Press.

23) Wollstonecraft. M. (2012). A Vindication of the Rights of Woman. UK: Andrews UK Limited. 